
\title{
28 Research Square \\ Role of Darunavir/cobicisitat in the Treatment of COVID-19: Initial Virological and Clinical Findings
}

\section{Liping Deng}

Wuhan University Zhongnan Hospital https://orcid.org/0000-0002-7651-0096

\section{Yong Xiong}

Zhongnan hospital Wuhan University

\section{TieLong Chen}

Wuhan University Zhongnan Hospital

Yongxi Zhang

Wuhan University Zhongnan Hospital

Mingqi Luo

Wuhan University Zhongnan Hospital

\section{Shicheng Gao}

Wuhan University Zhongnan Hospital

\section{Pingzheng Mo}

Zhongnan hospital

\section{Shihui Song}

Zhongnan hospital

\section{Zhiyong Ma}

Zhongnan hospital

\section{Xiaoping Chen}

Zhongnan hospital Wuhan University

\section{Ke Liang}

Zhongnan hospital wuhan University

\section{Hengning Ke ( $\nabla$ kehengning@znhospital.cn )}

Zhongnan Hospital of Wuhan University https://orcid.org/0000-0003-1185-5402

\section{Xinghuan Wang}

Zhongnan hospital Wuhan University

\section{Research Article}

Keywords: SARS-CoV-2, COVID-19, darunavir/cobicisitat(DRV/c), antiviral intervention

Posted Date: February 5th, 2021 
DOl: https://doi.org/10.21203/rs.3.rs-176224/v1

License: (c) (1) This work is licensed under a Creative Commons Attribution 4.0 International License. Read Full License 


\section{Abstract}

Background: COVID-19 still become a common threat to public health.In this study, we evaluated the antiviral effects and safety of darunavir/cobicisitat (DRV/c) in patients with confirmed COVID-19.

Patients and Methods: Totally 66 patients with COVID-19 infection who were admitted to Zhongnan Hospital of Wuhan University between February 3 and March 11, 2020 were collected. The patients were divided into the DRV/c group and the control group. The Primary endpoints was the time of SARS-CoV-2 nucleic acid conversion detected in respiratory specimens.

Results: A total of 66 subjects with confirmed SARS-CoV-2 infection were enrolled in this study, 32 subjects were enrolled in the DRV/c group and 34 in the control group. The mean time to nucleic acid conversion (NAC) was shorter in DRV/c group. The cumulative nucleic acid conversion rate (CNACR) in the DRV/C group was higher during the first 2 weeks, but the difference was not statistically significant. The proportion of fever during hospitalization in the DRV/C group was significantly lower than that in the control group (P value 0.01 ). It was found that in DRV/c group NAC of patients with duration from symptom onset to admission within 3 days was significantly shorter $(7.9 \pm 6.7$ days) than that of and above 3 days $(15.9 \pm 7.1$ days $)(P=0.01)$.

Conclusion: Although the combination of DRV/c and routine treatment for patients with non-severe COVID-19 can significantly reduce the proportion of fever after admission, but no significant differences were observed between the DRV/c group and the conventional therapy group, including overall time to nucleic acid conversion, safety and tolerability.

\section{Introduction}

The novel coronavirus disease 2019 (COVID-19) caused by SARS-CoV-2 has become a global pandemic[1]. The COVID-19 pandemic which probably is the most devastating one in the last 100 years after Spanish flu. The vaccine become available[2, 3], the outbreak is still out of control globally. A mutant strain of the coronavirus has been reported[4].COVID-19 still become a common threat to public health. The current COVID-19 pandemic has urged the scientific community internationally to find answers in terms of therapeutics and vaccines to control SARS-CoV-2.

Since the onset of COVID-19 outbreak, an in-vitro drug study has shown that some antiviral drugs may be effective, such as lopinavir, Remdesivir, and chloroquine[5]. The efficacy of these agents is still controversial due to limited randomized clinical trials proving their efficacy[6]. A recent global multicenter study shows that remdesivir may benefit hospitalized patients with COVID-19[7]. Remdesivir has received emergency approval in the United States for the treatment of COVID-19.

Lopinavir is antiretroviral protease inhibitors used in combination for the treatment of human immunodeficiency virus (HIV) infection and has limited side effects. An analysis of molecular dynamics simulations showed that the SARS-CoV-2 3CL pro-enzyme could be inhibited by the combination of 
lopinavir[8]. An in-vitro study has shown that lopinavir, ribavirin and IFN- $\beta 1 \mathrm{~b}$ may be effective for the treatment of SARS and MERS[9].Darunavir is an anti-HIV protease inhibitor [10] with the same target as lopinavir and better safety and tolerability $[11,12]$. Darunavir/Cobicistat (DRV/c) is a fixed-dose combination approved in China for the treatment of HIV-1 infection in combination use with other antiretroviral agents. We conducted this study aiming to evaluate the antiviral effects and safety of DRV/c in patients with confirmed COVID-19.

\section{Patients And Methods}

\section{Study design and participants}

This case series was approved by the Institutional Ethics Board of Zhongnan Hospital of Wuhan University (No. 2020011). The study consisted of a prospective series of patients with confirmed COVID19 who received DRV/c and conventional treatment were admitted to Zhongnan Hospital of Wuhan University from February 3,2020 , to March 11,2020 . The patients who voluntarily took DRV/c and were enrolled in DRV/c group. Screening for enrollment was performed after all patients signed written informed consent. A case series of COVID-19 patients as non-DRV/c control group was retrospectively reviewed, including patients who were hospitalized during the same period, met the same study criteria but did not receive investigational antivirals such as DRV/c, LPV/r, or remdesivir, etc.

Zhongnan Hospital is located in Wuhan (Hubei Province), which was once a endemic area of COVID-19. It is a major teaching hospital and was responsible for the treatment of COVID-19, as assigned by the People's Republic of China. All patients with COVID-19 enrolled in this study were diagnosed according to World Health Organization interim guidance [13].

\section{Inclusion or ExclusionCriteria}

Inclusion Criteria: Age between 18-65; Confirmed diagnosis of COVID-19; Relevant clinical symptoms onset until diagnosis within 10 days (such as fever, cough, etc).

Exclusion Criteria: Patients with known hypersensitivity to DRV/c; Patients planned for or with ongoing use of drugs that interact with DRV/c (including: drugs that are highly CYP3A dependent and have elevated plasma concentrations associated with serious and/or life-threatening events [narrow therapeutic index], CYP3A inducers [refer to package insert]), and cannot be discontinued or switched to other drugs; Alanine aminotransferase (ALT )/aspartate aminotransferase (AST) elevation greater than 5 times the upper limit of normal, or child-Pugh grade C; Critically ill patients with expected survival of $<48$ hours; Women of childbearing potential with a positive pregnancy test; Participants of other clinical trials within 3 months; HIV-infected patients; Inappropriate in the opinion of the investigator.

\section{Investigational drug and Group}

DRV/c (800mg/150mg, one tablet daily with meal, Janssen Ortho, LLC, Product Batch Number: IKZ1000); 
DRV/c group: $\mathrm{DRV} / \mathrm{c} \varangle 800 / 150 \mathrm{mg}$ once daily for 2 weeks $₫+$ conventional treatment;

Conventional treatment[14]: included symptomatic supportive treatment (such as oxygen inhalation, prevention and treatment of infection), arbidol antiviral, Thymalfasin or gamma globulin immunotherapy, corticosteroid therapy, detailed as follows.

Some patients received other antiviral treatment with arbidol (200 mg twice daily), interferon-alpha inhalation (50 $\mathrm{\mu g}$ twice daily) and immunomodulator Thymalfasin $(1.6 \mathrm{mg}$,ih,qod) for two weeks. Patients received treatment with corticosteroids ( $40-80 \mathrm{mg} /$ day) and gamma globulin (10-20 g/day) for 3-5 days, when their resting respiratory rate was $>30$ per min, oxygen saturation was $<93 \%$ without oxygen, or multiple pulmonary lobes showed more than $50 \%$ progression of disease within $48 \mathrm{~h}$ of imaging. Patients also received treatment with probiotics in most cases. Quinolones and second-generation beta-lactams (oral and intravenous) were administered if fever lasted longer than seven days or C-reactive protein levels were $>20 \mathrm{mg} / \mathrm{L}$ (normal range 0-10 mg/L). The discharge criteria were: (i) afebrile for at least 3 days, (ii) obvious alleviation of respiratory symptoms, (iii) improvement in radiological abnormalities on chest computed tomography (CT) or X-ray and (iv) two consecutive negative detections of SARS- CoV-2 at least $24 \mathrm{~h}$ apart.

\section{Efficacy endpoints (primary and secondary endpoints)}

Primary endpoints: The time to SARS-CoV-2nucleic acid conversion detected in respiratory specimens (such as throat swabs);

Secondary endpoints: all-cause mortality, time to normal body temperature, number of inpatient days, admission to intensive care unit (ICU) or not, invasive mechanical ventilation or not, lung computed tomographic (CT) improvement, and normalization rate of inflammatory indicators.

\section{Safety Endpoints}

Safety endpoints: adverse events, laboratory tests (hematology, liver and kidney function, blood glucose, electrolytes, lipids, blood amylase, lipase, myocardial enzymes, urine routine), electrocardiogram.

\section{Laboratory confirmation}

COVID-19 was confirmed by detectingSARS-CoV-2RNA in throat swab samples using aSARS-CoV2nucleic acid detection kit according to the manufacturer's protocol (Shanghai BioGerm Medical Biotechnology Co.,Ltd)[15]. Virus detection by throat swab was repeated every $24-72 \mathrm{~h}$. Throat swab specimens were collected from all patients upon admission and tested by real-time polymerase chain reaction (RT-PCR) forSARS-CoV-2RNA within 3 hours[16]. Laboratory tests were conducted upon admission, Laboratory testing items were similar to our previous reports[17].

\section{Data collection}


The medical records of patients were analyzed by the research team of the Department of Infectious Disease at Zhongnan Hospital of Wuhan University. Data collection was similar to our previous reports[17]. Epidemiological, clinical, laboratory, and radiological characteristics, along with treatment and outcome data, were obtained from electronic medical records. The data were reviewed by a trained team of physicians. The date of disease onset was defined as the day when the symptoms were noticed by the patient, symptoms were defined as fever, cough, chest tightness, dyspnea, muscle pain et al.

The time to nucleic acid conversion was defined as two consecutive negative detections in throat swabs taken one day apart, and the conversion time was set at the time of the previous day. Adverse reactions after administration were collected during daily rounds.

Acute respiratory distress syndrome (ARDS) was defined according to the Berlin definition [18]. The duration from disease onset to hospital admission, dyspnea, ARDS, intensive care unit (ICU) admission, and discharge were also recorded.

\section{Statistical analysis}

Categorical variables were described as frequency rates and percentages, and continuous variables were described using mean, standard deviation, median, and interquartile range (IQR) values. Means for continuous variables were compared using independent group t-test when the data were normally distributed. Proportions for categorical variables were compared using the $\chi 2$ test, although the Fisher exact test was used when the data were limited. All statistical analyses were performed using Statistical Package for the Social Sciences (SPSS) version 22.0 software (SPSS Inc., Chicago, IL USA).

\section{Results}

\section{Demographic and clinical characteristics}

A total of 66 subjects with confirmedSARS-CoV-2infection were enrolled in this study, among whom 22 (33.3\%) were male subjects and the cohort had a mean age of 45 years (20-65). All cases had no history of smoking, no chronic lung disease (eg, COPD, tuberculosis), and no history of kidney disease or tumors. 30 patients $(45.5 \%)$ had at least one underlying comorbidity, including hypertension, diabetes, cardiovascular and cerebrovascular diseases, hepatitis $\mathrm{B}$, and hepatitis $\mathrm{C}$. Common symptoms included fever (47 cases [71.2\%]), dry cough (24 cases [36.4\%]), and fatigue (17 cases, [25.8\%]). 4 cases $(6.1 \%)$ were mild, 57 cases $(86.4 \%)$ were moderate, and 5 cases $(7.6 \%)$ were severe. The mean time from disease onset to hospital admission was 5.5 days (1-10). 32 subjects were enrolled in the DRV/C group and 34 in the control group. The baseline status of the two groups at admission was similar (see Table 1). Table 2 shows the laboratory and radiologic findings on admission. At the time of admission, all cases were detected negative in throat swabs for influenza virus, parainfluenza virus, respiratory syncytial virus, adenovirus nucleic acid, chlamydia, and mycoplasma antibodies. The test results were in the normal range for AMY, LIP, LDL, total cholesterol, triglyceride, D2-Dimer, IL-6, CRP and PCT. The main laboratory abnormalities were decline of white blood cells and lymphocytes, and elevation of blood glucose, CK, and 
ESR (see Table 2). The pulmonary imaging of 66 cases at the time of admission showed that 5 cases $(7.6 \%)$ had no obvious lesions, 16 cases $(24.2 \%)$ had a little exudation or patchy shadow in the unilateral lungs, and 45 cases (68. 1\%) showed typical double-lung ground glass or patchy exudative lesions. There was no significant difference in relevant laboratory tests at baseline between the two groups.

\section{The time to nucleic acid conversion in throat swabs and cumulative conversion rates}

The time to nucleic acid conversion (NAC) of DRV/c group VS control group was $7.8 \pm 6.0$ days VS $10.4 \pm$ 8.4 days from start of the treatment, and $14.1 \pm 7.8$ days VS $16.7 \pm 8.4$ days from symptom onset. The mean time to NAC was shorter in DRV/c group than in control group, but the difference was not statistically significant (see Table 3, Figure 1). After antiviral treatment, throat swab nucleic acid was dynamically detected every 24-72 hours. On Day 3, Day 6, Day 9, Day 12, Day 15, Day 18, Day 24, Day 27 and Day 30 , the cumulative conversion rates of DRV/c group VS control group were: $35.5 \%$ vs $21.2 \%$, $54.8 \%$ vs $39.4 \%, 71.0 \%$ vs $57.6 \%, 77.4 \%$ vs $63.6 \%, 90.3 \%$ vs $75.8 \%, 90.3 \%$ vs $90.9 \%, 93.5 \%$ vs $93.9 \%$, $96.8 \%$ vs $93.9 \%, 100 \%$ vs $93.9 \% 100.0 \%$ vs $93.9 \%$, respectively. During observation periods, no case was found that the nucleic acid was converted from negative to positive. The cumulative nucleic acid conversion rate of DRV/c was higher than that of the control group during the first 2 weeks, but the difference was not statistically significant (see Table 4, Figure 2). The time from symptom onset to admission was further grouped by 3 days (< or >= 3 days from symptom onset to admission) (Table 5) and time to nucleic acid conversion was compared between groups. It was found that in the DRV/c group the time from symptom onset to nucleic acid conversion for the subjects with duration from symptom onset to admission within 3 days was significantly shorter (7.9 \pm 6.7 days) than that of and above 3 days (15.9 \pm 7.1 days). The $P$ value was 0.01 (Figure 1$)$. Within these subgroups there was no significant difference between the DRV/c and control group.

\section{Treatment and Clinical outcomes}

Overall, oxygen therapy, mechanical ventilation, combination therapy with arbidol, interferon inhalation, corticosteroid therapy was initiated in $46.2 \%, 3.0 \%, 39.4 \%, 21.2 \%$ and $42.4 \%$ of patients, respectively. Combination therapy with Thymalfasin and gamma globulin were initiated in $33.3 \%$ and $10.6 \%$ of patients, respectively; 9 cases had disease progression during hospitalization and 2 cases were transferred to ICU for concurrent tracheal intubation and ventilator-assisted breathing; and there was no significant difference in other treatments between the two groups (see Table 3 for details). 40 cases still had fever during hospitalization, but the proportion of fever during hospitalization in the DRV/C group was significantly lower than that in the control group (P value 0.01 ), which made the difference statistically significant. The average number of days of fever during hospitalization was 3.5 days (1-11) without significant difference between the groups. $34.4 \%$ of patients showed lesions progression in lung CT review at an average interval of 5 days in hospital, $80.3 \%$ of patients had CT improvement at an average interval of 10 days in hospital, and the difference between those receiving DTR/c vs. not was not statistically significant. There were no case of death in this study. All patients were discharged after nucleic acid conversion. The average length of stay was 13.1 (3-39) days (Table 3). 


\section{Safety}

There was no case of death in 32 subjects treated with DRV/c. 1 case was discontinued with DRV/c (not related to investigational drug) due to respiratory failure; the remaining subjects completed 14-day administration and no subject withdrew due to AEs. Only one subject experienced a serious adverse event, ie, respiratory failure as described above. Only one adverse reaction of upset stomach on the day of administration was noted. There were no other adverse reactions reported. Changes in baseline abnormal values (WBC, L, CD4, CD8, CD3, B, NK cell counts, ALT, CK and GLU) after treatment are presented in Figure 3, reflecting significant improvement from baseline. No apparent laboratory abnormalities related with investigational drug were observed.

\section{Discussion And Conclusions}

Similar to previous reports[19] 囚in this study adding DRV/c to the conventional treatment of COVID-19 patients, there were no statistically significant differences in the average time to nucleic acid conversion in throat swabs, the time from symptom onset to conversion and the time for start of treatment to conversion. In addition, in the first two weeks of treatment the rate of nucleic acid conversion in throat swabs was higher in the DRV/c group than that in the conventional treatment group, but the difference was not statistically significant. We know that DRV is an aspartic protease inhibitor. By contrast, the SARS-CoV-2 main protease is a cysteine protease .We also have seen no in-vitro activity of DRV at concentrations of $100 \mathrm{uM}$, which is much higher than the median trough concentrations observed with dosing of DRV/c QD (3.4uM)[20].

SARS-CoV-2 infection presents mainly with respiratory symptoms. The full spectrum of Covid-19 ranges from mild, self-limiting respiratory tract illness to severe progress pneumonia, multiorgan failure, and death. Of the 66 subjects in this group, the average age was 45 years (20-65), 22 cases were male (33.3\%), and 30 cases were medical workers (45.5\%). The average time from symptom onset to admission was 5.5 days. Only 5 cases $(7.6 \%)$ were severe on admission and 30 cases (45.5\%) had at least one comorbidity. The baseline data of the two groups were consistent. The mortality rate of COVID19 hospitalized patients reported in different regions and populations is $1.4 \%-28.3 \%[16,21-23]$, and the mortality rate has been reported as high as $61.5 \%$ (32/52) [24]. Olderly, male sex, and the presence of baseline comorbidities have been identified as risk factors for death or progression to severe cases. The group of subjects in this study was younger, mainly female, and had no complications and death during the course of the disease, which further presented that this group is mainly with non-severe cases, and also explained the better prognosis.

Common symptoms of the two groups of patients mainly were: fever, dry cough, and fatigue. There was no difference of average maximum body temperature before admission between the two groups. Key laboratory abnormalities were consistent with common symptoms reported in previous studies that mainly include declined white blood cell count and lymphocyte count, ESR and lung CT typically with exudative lesions in both lungs[15]. Significant elevation of LDH, D-dimer, IL-6 and CRP in COVID-19 
patients were reported in previous studies related with severe cases [16, 21, 25]. The indicators described above were in normal range in this study, which might relate to no severe cases in this study.

There is no confirmed effective drug againstSARS-CoV-2currently. In the outbreak of SARS in 2003, lopinavir and ribavirin were effective against SARS virus in vitro cultur ${ }^{[9]}$. In some small sample studies, LPV/r combined with ribavirin could significantly decreased mortality, alleviated symptoms, and decreased the rate of progression to severe cases and the rate of tracheal intubation. However, this treatment needed to be applied in the early stages of the disease soon after symptom onset. Otherwise, no efficacy was observed in salvage therapy of severe SARS cases[9]. A recent randomized, open-label, controlled study of LPV/r in 199 severe COVID-19 subjects did not show favorable clinical outcome in critically ill subjects[26]. It might be result of late intervention of antiviral treatment as $54.8 \%$ of subjects had symptoms more than 12 days at enrollment. Viral nucleic acid could be detected in $40.7 \%$ of subjects of LPV/r group on Day 28 suggesting the persistentence of viral nucleic acid, which might lead to progression to severe cases. Another recent small sample clinical study showed[27] that the combination treatment with LPV/r and adjuvant drugs has a more evident therapeutic effect in lowering the body temperature and restoring normal physiological mechanisms with no evident toxic and side effects.

In a 5-year data collection on oseltamivir for the treatment of influenza, the use of oseltamivir within 6 hours since influenza symptoms onset could significantly shorten the inpatient days and decrease mortality[28]. Both SARS and COVID-19 patients developed to rapid progression in about one week[29, 30], and some of them progressed rapidly to ARDS leading to death. In previous SARS studies, nucleic acid detections of nasopharynx achieved a peak in about 10 days without any antiviral intervention, while most of them decreased after around one week with early antiviral treatment ${ }^{5}$, suggesting that early antiviral therapy should be applied to respiratory viral infections, and clearance of the virus as early as possible might mitigate damage caused by cytokine storm ${ }^{[29,31] 7,30}$. In this study, it was found that in the $\mathrm{DRV} / \mathrm{c}$ group the time from symptom onset to nucleic acid conversion for the subjects with duration from symptom onset to admission within 3 days was significantly shorter than that of and above 3 days, which was $7.9 \pm 6.7$ days \& $15.9 \pm 7.1$ days, respectively. However, the difference was not statistically significant compared to control group. Further randomized, double-blind, large sample studies are still required to observe whether early antiviral therapy can significantly shorten time to nucleic acid conversion and mitigate the risk of progression to severe cases.

In terms of safety in this study, only one patient experienced an epigastric discomfort at the initial administration. There were no other adverse reactions reported. Except for one subject transferred to the ICU due to progression of lung lesions, all other subjects completed 14-day treatment with good tolerability of DRV/c. The abnormal rates of liver and kidney function were similar between the two groups before and after administration. Transient ALT elevations (not exceeding 2 times the upper limit of normal) were observed after treatment for one week, and significantly improved after two weeks without special treatment. The blood lipids and pancreatic enzymes were in normal range before and after treatment, suggesting that the safety of the two groups was comparable. The safety and tolerability 
profile of DRV/c group observed in this study was consistent with the known safety profile of this drug[10, 32]

Of course, there were some deficiencies in this study. Firstly, this study was not a randomized, open-label study. However, the subjects in control group were patients admitted to the hospital during the same period and enrolled per eligibility criteria. Therefore, the basic characteristics of the two groups were consistent. Secondly, the sample size was small in this study, which might lead to bias of the result. In addition, this was a single-center study with fewer critically ill patients enrolled, that might not reflect the efficacy in various populations.

In conclusion, Although the combination of DRV/c and routine treatment for patients with non-severe COVID-19 can significantly reduce the proportion of fever after admission, but no significant differences were observed between the DRV/c group (DRV/c + conventional therapy) and the conventional therapy only group, including overall time to nucleic acid conversion, safety and tolerability. Further assessment on the efficacy of DRV/c will be required in the treatment of COVID-19 prior to considering this as a treatment option for patients with COVID-19, with thought given to time of therapy initiation relative to symptom onset. Based on invitro data, NEJM data on LPV/r and structure of SARS CoV-2 protease enzyme, should we look for alternative agents?

\section{Declarations}

\section{Acknowledgements}

We would like to acknowledge and thank the patients including in this study, and all staff in the Department of Infectious Diseases, Zhongnan Hospital of Wuhan University.

\section{Authors' contributions}

Concept and design: Yong Xiong, Liping Deng, Xinghuan Wang , Hengning Ke.

Acquisition, analysis, or interpretation of data: TieLong Chen, Yongxi Zhang Pingzheng Mo, Shicheng Gao, Zhiyong Ma, Shihui Song, Mingqi Luo.Ke Liang. Drafting of the manuscript: Liping Deng, Tielong

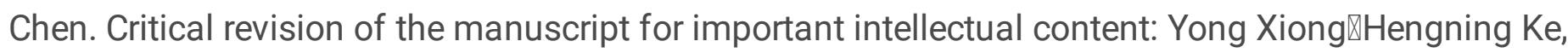
Xinghuan Wang. The author(s) read and approved the final manuscript.

\section{Funding}

No funding.

\section{Availability of data and materials}

The datasets supporting the conclusions of this article are included within the article. And further detailed datasets for the current study are available from the corresponding author on reasonable request. 


\section{Ethics approval and consent to participate}

This study was conducted according to the principles expressed in the Declaration of Helsinki, and was approved by the ethics committee of Zhongnan Hospital of Wuhan University (No. 2020011). Written consent forms were obtained from the patients after gave them appropriate information.

\section{Consent for publication}

Written consent forms for publication were obtained from the patients or their clients after gave them appropriate information.

\section{References}

1. WHO.Coronavirus disease 2019 (COVID-19) Situation Report - 64 [https://www.who.int/docs/default-source/coronaviruse/situation-reports/20200324-sitrep-64-covid19.pdf?sfvrsn=703b2c40_2]

2. Polack FP, Thomas SJ, Kitchin N, Absalon J, Gurtman A, Lockhart S, Perez JL, Perez Marc G, Moreira ED, Zerbini $C$ et al. Safety and Efficacy of the BNT162b2 mRNA Covid-19 Vaccine. N Engl J Med 2020;383(27):2603-2615. doi: 10.1056/NEJMoa2034577 [published Online First: 2020/12/11]

3. Zhu FC, Li YH, Guan XH, Hou LH, Wang WJ, Li JX, Wu SP, Wang BS, Wang Z, Wang L et al. Safety, tolerability, and immunogenicity of a recombinant adenovirus type- 5 vectored COVID-19 vaccine: a dose-escalation, open-label, non-randomised, first-in-human trial. Lancet 2020;395(10240):18451854. doi: 10.1016/S0140-6736(20)31208-3 [published Online First: 2020/05/26]

4. Fang S, Li K, Shen J, Liu S, Liu J, Yang L, Hu CD, Wan J. GESS: a database of global evaluation of SARS-CoV-2/hCoV-19 sequences. Nucleic Acids Res 2021;49(D1):D706-D714. doi: 10.1093/nar/gkaa808 [published Online First: 2020/10/13]

5. Wang M, Cao R, Zhang L, Yang X, Liu J, Xu M, Shi Z, Hu Z, Zhong W, Xiao G. Remdesivir and chloroquine effectively inhibit the recently emerged novel coronavirus (2019-nCoV) in vitro. Cell Res 2020;30(3):269-271. doi: 10.1038/s41422-020-0282-0 [published Online First: 2020/02/06]

6. Jomah S, Asdaq SMB, Al-Yamani MJ. Clinical efficacy of antivirals against novel coronavirus (COVID-19): A review. J Infect Public Health 2020;13(9):1187-1195. doi: 10.1016/j.jiph.2020.07.013 [published Online First: 2020/08/11]

7. Beigel JH, Tomashek KM, Dodd LE, Mehta AK, Zingman BS, Kalil AC, Hohmann E, Chu HY, Luetkemeyer A, Kline S et al. Remdesivir for the Treatment of Covid-19 - Final Report. N Engl J Med 2020 doi: 10.1056/NEJMoa2007764 [published Online First: 2020/05/24]

8. Nukoolkarn V, Lee VS, Malaisree M, Aruksakulwong O, Hannongbua S. Molecular dynamic simulations analysis of ritonavir and lopinavir as SARS-CoV 3CL(pro) inhibitors. J Theor Biol 2008;254(4):861-867. doi: 10.1016/j.jtbi.2008.07.030

9. Chu CM, Cheng VC, Hung IF, Wong MM, Chan KH, Chan KS, Kao RY, Poon LL, Wong CL, Guan Y et al. Role of lopinavir/ritonavir in the treatment of SARS: initial virological and clinical findings. Thorax 
2004;59(3):252-256. doi: 10.1136/thorax.2003.012658 [published Online First: 2004/02/27]

10. Mallolas J. Darunavir Stands Up as Preferred HIV Protease Inhibitor. AIDS Rev 2017;19(2):105-112. [published Online First: 2017/07/01]

11. Venter WDF, Moorhouse M, Sokhela S, Serenata C, Akpomiemie G, Qavi A, Mashabane N, Arulappan N, Sim JW, Sinxadi PZ et al. Low-dose ritonavir-boosted darunavir once daily versus ritonavir-boosted lopinavir for participants with less than 50 HIV RNA copies per $\mathrm{mL}$ (WRHI 052): a randomised, openlabel, phase 3, non-inferiority trial. Lancet HIV 2019;6(7):e428-e437. doi: 10.1016/s23523018(19)30081-5 [published Online First: 2019/06/17]

12. Lathouwers E, De Meyer S, Dierynck I, Van de Casteele T, Lavreys L, de Bethune MP, Picchio G. Virological characterization of patients failing darunavir/ritonavir or lopinavir/ritonavir treatment in the ARTEMIS study: 96-week analysis. Antivir Ther 2011;16(1):99-108. doi: 10.3851/imp1719 [published Online First: 2011/02/12]

13. WHO.Clinical management of severe acute respiratory infection when Novel coronavirus (nCoV) infection is suspected: interim guidance. [https://www.who.int/publications-detail/clinicalmanagement-of-severe-acute-respiratory-infection-when-novel-coronavirus-(ncov)-infection-issuspected]

14. China. NHCo. Diagnosis and treatment of pneumonia caused by 2019 new coronavirus (trial version 6). $\triangle E B / O L] . ~$. http://wwwnhcgovcn/yzygj/s7653p/202002/8334a8326dd94d329df351d7da8aefc2shtml

15. Mo P, Xing Y, Xiao Y, Deng L, Zhao Q, Wang H, Xiong Y, Cheng Z, Gao S, Liang K et al. Clinical characteristics of refractory COVID-19 pneumonia in Wuhan, China. Clin Infect Dis 2020 doi: 10.1093/cid/ciaa270 [published Online First: 2020/03/17]

16. Wang D, Hu B, Hu C, Zhu F, Liu X, Zhang J, Wang B, Xiang H, Cheng Z, Xiong Y et al. Clinical Characteristics of 138 Hospitalized Patients With 2019 Novel Coronavirus-Infected Pneumonia in Wuhan, China. Jama 2020 doi: 10.1001/jama.2020.1585 [published Online First: 2020/02/08]

17. Chen T, Dai Z, Mo P, Li X, Ma Z, Song S, Chen X, Luo M, Liang K, Gao S et al. Clinical characteristics and outcomes of older patients with coronavirus disease 2019 (COVID-19) in Wuhan, China (2019): a single-centered, retrospective study. J Gerontol A Biol Sci Med Sci 2020 doi: 10.1093/gerona/glaa089 [published Online First: 2020/04/13]

18. Ranieri VM, Rubenfeld GD, Thompson BT, Ferguson ND, Caldwell E, Fan E, Camporota L, Slutsky AS. Acute respiratory distress syndrome: the Berlin Definition. Jama 2012;307(23):2526-2533. doi: 10.1001/jama.2012.5669 [published Online First: 2012/07/17]

19. Chen J, Xia L, Liu L, Xu Q, Ling Y, Huang D, Huang W, Song S, Xu S, Shen Y et al. Antiviral Activity and Safety of Darunavir/Cobicistat for the Treatment of COVID-19. Open Forum Infect Dis 2020;7(7):ofaa241. doi: 10.1093/ofid/ofaa241 [published Online First: 2020/07/17]

20. De Meyer S, Bojkova D, Cinati J, Van Damme E, Buyck C, Van Loock M, Woodfall B, Ciesek S. Lack of Antiviral Activity of Darunavir against SARS-CoV-2. medRxiv 2020 
21. Zhou F, Yu T, Du R, Fan G, Liu Y, Liu Z, Xiang J, Wang Y, Song B, Gu X et al. Clinical course and risk factors for mortality of adult inpatients with COVID-19 in Wuhan, China: a retrospective cohort study. Lancet 2020;395(10229):1054-1062. doi: 10.1016/s0140-6736(20)30566-3 [published Online First: 2020/03/15]

22. Guan WJ, Ni ZY, Hu Y, Liang WH, Ou CQ, He JX, Liu L, Shan H, Lei CL, Hui DSC et al. Clinical Characteristics of Coronavirus Disease 2019 in China. N Engl J Med 2020 doi:

10.1056/NEJMoa2002032 [published Online First: 2020/02/29]

23. Huang C, Wang Y, Li X, Ren L, Zhao J, Hu Y, Zhang L, Fan G, Xu J, Gu X et al. Clinical features of patients infected with 2019 novel coronavirus in Wuhan, China. Lancet 2020 doi: 10.1016/s01406736(20)30183-5 [published Online First: 2020/01/28]

24. Yang $X, Y u$ Y, Xu J, Shu H, Xia J, Liu H, Wu Y, Zhang L, Yu Z, Fang M et al. Clinical course and outcomes of critically ill patients with SARS-CoV-2 pneumonia in Wuhan, China: a single-centered, retrospective, observational study. Lancet Respir Med 2020 doi: 10.1016/s2213-2600(20)30079-5 [published Online First: 2020/02/28]

25. Wu C, Chen X, Cai Y, Xia J, Zhou X, Xu S, Huang H, Zhang L, Zhou X, Du C et al. Risk Factors Associated With Acute Respiratory Distress Syndrome and Death in Patients With Coronavirus Disease 2019 Pneumonia in Wuhan, China. JAMA Intern Med 2020 doi: 10.1001/jamainternmed.2020.0994

26. Cao B, Wang Y, Wen D, Liu W, Wang J, Fan G, Ruan L, Song B, Cai Y, Wei M et al. A Trial of LopinavirRitonavir in Adults Hospitalized with Severe Covid-19. N Engl J Med 2020 doi: 10.1056/NEJMoa2001282 [published Online First: 2020/03/19]

27. Ye XT, Luo YL, Xia SC, Sun QF, Ding JG, Zhou Y, Chen W, Wang XF, Zhang WW, Du WJ et al. Clinical efficacy of lopinavir/ritonavir in the treatment of Coronavirus disease 2019. Eur Rev Med Pharmacol Sci 2020;24(6):3390-3396. doi: 10.26355/eurrev_202003_20706

28. Katzen J, Kohn R, Houk JL, Ison MG. Early Oseltamivir After Hospital Admission Is Associated With Shortened Hospitalization: A 5-Year Analysis of Oseltamivir Timing and Clinical Outcomes. Clin Infect Dis 2019;69(1):52-58. doi: 10.1093/cid/ciy860 [published Online First: 2018/10/12]

29. Yao TT, Qian JD, Zhu WY, Wang Y, Wang GQ. A systematic review of lopinavir therapy for SARS coronavirus and MERS coronavirus-A possible reference for coronavirus disease-19 treatment option. J Med Virol 2020 doi: 10.1002/jmv.25729 [published Online First: 2020/02/28]

30. Pan Y, Zhang D, Yang P, Poon LLM, Wang Q. Viral load of SARS-CoV-2 in clinical samples. Lancet Infect Dis 2020 doi: 10.1016/s1473-3099(20)30113-4 [published Online First: 2020/02/28]

31. Kandeel M, Ibrahim AA, Fayez M, Al-Nazawi M. From SARS and MERS CoVs to SARS-CoV-2: moving toward more biased codon usage in viral structural and non-structural genes. J Med Virol 2020 doi: 10.1002/jmv.25754

32. Huhn GD, Eron JJ, Girard PM, Orkin C, Molina JM, DeJesus E, Petrovic R, Luo D, Van Landuyt E, Lathouwers $\mathrm{E}$ et al. Darunavir/cobicistat/emtricitabine/tenofovir alafenamide in treatmentexperienced, virologically suppressed patients with HIV-1: subgroup analyses of the phase 3 
EMERALD study. AIDS Res Ther 2019;16(1):23. doi: 10.1186/s12981-019-0235-1 [published Online First: 2019/08/30]

\section{Tables}


Table 1

Baseline characteristics of patients with COVID-19.

\begin{tabular}{|c|c|c|c|c|}
\hline & \multicolumn{3}{|c|}{ No. (\%) } & \multirow{2}{*}{$\begin{array}{l}P \\
\text { value }\end{array}$} \\
\hline & $\begin{array}{l}\text { Total }(n= \\
66)\end{array}$ & $\begin{array}{l}\text { DRV/c }(n= \\
32)\end{array}$ & $\begin{array}{l}\text { Control }(n= \\
34)\end{array}$ & \\
\hline Age, median (IQR), years & $45(20-65)$ & $46(22-65)$ & $42(20-62)$ & 0.28 \\
\hline Male & 22(33.3) & $11(34.4)$ & $11(32.4)$ & 0.86 \\
\hline Health worker & $30(45.5)$ & $17(53.1)$ & 13(38.3) & 0.23 \\
\hline \multicolumn{5}{|l|}{ Comorbidities, median (IQR), No. } \\
\hline Hypertension & $9(13.6)$ & $5(15.6)$ & $4(11.8)$ & 0.73 \\
\hline Diabetes & $6(9.1)$ & $5(15.6)$ & $1(2.9)$ & 0.10 \\
\hline Other Cardiovascular diseases & $4(6.1)$ & $3(9.4)$ & $1(2.9)$ & 0.35 \\
\hline Cerebrovascular diseases & $1(1.5)$ & $1(3.1)$ & 0 & 0.49 \\
\hline HBsAg-positive & $8(12.1)$ & $2(6.3)$ & $6(17.6)$ & 0.26 \\
\hline Anti-HCV positive & $2(3.0)$ & $1(3.1)$ & $1(2.9)$ & 1.0 \\
\hline \multicolumn{5}{|l|}{ Symptoms and signs } \\
\hline Fever & $47(71.2)$ & $20(62.5)$ & $27(79.4)$ & 0.13 \\
\hline Maximum temperature, ${ }^{\circ} \mathrm{C}$ & $\begin{array}{l}38.4(37- \\
40.2)\end{array}$ & $\begin{array}{l}38.3(37- \\
39.5)\end{array}$ & $\begin{array}{l}38.5(37- \\
40.2)\end{array}$ & 0.32 \\
\hline Cough & $24(36.4)$ & $13(40.6)$ & 11(32.4) & 0.49 \\
\hline Chest distress & $10(15.2)$ & $6(18.8)$ & $4(11.8)$ & 0.51 \\
\hline Fatigue & $17(25.8)$ & $11(34.4)$ & $6(17.6)$ & 0.12 \\
\hline Breath shortness & $7(10.6)$ & $4(12.5)$ & $3(8.8)$ & 0.71 \\
\hline Myalgia or arthralgia & 10(15.2) & $4(12.5)$ & $6(17.6)$ & 0.73 \\
\hline Anorexia & $2(3.0)$ & $1(3.1)$ & $1(2.9)$ & 1.0 \\
\hline Headache & $5(7.6)$ & $4(12.5)$ & $1(2.9)$ & 0.19 \\
\hline Diarrhea & $4(6.1)$ & $2(6.3)$ & $2(5.9)$ & 1.0 \\
\hline Nausea/Vomiting & $4(6.1)$ & $1(3.1)$ & $3(8.8)$ & 0.61 \\
\hline Dizziness & $3(4.5)$ & $2(6.3)$ & $1(2.9)$ & 0.61 \\
\hline
\end{tabular}

IQR, interquartile range; COVID, coronavirus disease; No., number; HBsAg, hepatitis B surface antigen; HCV, hepatitis C virus; 


\begin{tabular}{|c|c|c|c|c|}
\hline & \multicolumn{3}{|c|}{ No. (\%) } & \multirow{2}{*}{$\begin{array}{l}P \\
\text { value }\end{array}$} \\
\hline & $\begin{array}{l}\text { Total }(n= \\
66)\end{array}$ & $\begin{array}{l}\text { DRV/c }(n= \\
32)\end{array}$ & $\begin{array}{l}\text { Control }(n= \\
\text { 34) }\end{array}$ & \\
\hline Dyspnea & $2(3.0)$ & $1(3.1)$ & $1(2.9)$ & 1.0 \\
\hline \multicolumn{5}{|l|}{ Severity assessment at admission } \\
\hline Mild & $4(6.1)$ & $3(9.4)$ & $1(2.9)$ & 0.35 \\
\hline Moderate & $57(86.4)$ & 26(81.3) & $31(91.2)$ & 0.30 \\
\hline Severe & $5(7.6)$ & $3(9.4)$ & $2(5.9)$ & 0.67 \\
\hline $\begin{array}{l}\text { Time from illness onset to first hospital } \\
\text { admission (days) }\end{array}$ & $5.5(1-10)$ & $5.4(2-10)$ & $5.6(1-10)$ & 0.74 \\
\hline
\end{tabular}


Table 2

Laboratory and radiological findings of patients with COVID-19.

\section{Normal \\ range}

No.(\%)

\begin{tabular}{|c|c|}
\hline $\begin{array}{l}\text { Total }(\mathrm{n}= \\
66)\end{array}$ & DRV/c(n = \\
\hline
\end{tabular}

$P$
value

\section{Blood routine}

White blood cell count, $\times 10^{9} / \mathrm{L}$

$<4 \times 10^{9} /$ L, No. $(\%)$

$>10 \times 10^{9} /$ L, No. $(\%)$

Lymphocyte count, $\times 10^{9} / \mathrm{L}$

$<1.0 \times 10^{9} / \mathrm{L}$, No. $(\%)$

Platelet count, $\times 10^{9} / \mathrm{L}$

$<100 \times 10^{9} /$ L, No. $(\%)$

Blood biochemistry

Alanine aminotransferase, $\quad 9-50$

$\mathrm{U} / \mathrm{L}$

$>50 \mathrm{U} / \mathrm{L}$, No. $(\%)$

Aspartate aminotransferase, $\mathrm{U} / \mathrm{L}$

$>40 \mathrm{U} / \mathrm{L}$, No. $(\%)$

GLU mmol/L

$>7 \mathrm{mmol} / \mathrm{L}$, No. (\%)

Creatine kinase, $\mathrm{U} / \mathrm{L}$

$>171 \mathrm{U} / \mathrm{L}$, No. $(\%)$

Infection-related biomarkers

ESR, $\mathrm{mm} / \mathrm{h}$

$<171$
$3.5-9.5$

$4.2(0.9-$

10.7)

$31(47.0)$

1(1.5)

$1.1-3.2$

$1.1(0.3-2.5)$

$34(51.5)$

$125-350$

187(83-

387)

$5(7.6)$

$26(5-180)$

$22(5-55)$

29(7-180)

0.24

6(9.1)

1(3.1)

$5(14.7)$

0.20

15-40

28(9-88)

24(9-71)

32(12-88)

0.07

10(15.2)

2(6.3)

8(23.5)

0.08

$3.9-6.1$

6.3(4-14)

6.6(4.1-

13.8)

5.9(4.6-

12.7)

5(14.7)

0.15

15(22.7)

130(25-

1133)

11(16.7)

10(31.3)

122(25-

1133)

5(15.6)

6(17.6)

1.0

138(132-

882)

0.74

$31(2-79)$

20(2-79)

24(2-59)

0.35

IQR, interquartile range; erythrocyte sedimentation rate, ESR; na., not available; No., number. Total,49 caes; DRV/c,31 cases,control,18 cases. 


\begin{tabular}{|c|c|c|c|c|c|}
\hline & \multirow{2}{*}{$\begin{array}{l}\text { Normal } \\
\text { range }\end{array}$} & \multicolumn{3}{|c|}{ No.(\%) } & \multirow{2}{*}{$\begin{array}{l}P \\
\text { value }\end{array}$} \\
\hline & & $\begin{array}{l}\text { Total }(n= \\
66)\end{array}$ & $\begin{array}{l}\mathrm{DRV} / \mathrm{c}(\mathrm{n}= \\
32)\end{array}$ & $\begin{array}{l}\text { Control }(n= \\
34)\end{array}$ & \\
\hline > 15 mm/h, No. (\%) & & $39(59.1)$ & $17(53.1)$ & $22(64.7)$ & 0.34 \\
\hline CD3 + T cell(cells /ul) & $805-4459$ & $\begin{array}{l}912(183- \\
2276)\end{array}$ & $\begin{array}{l}860(183- \\
2196)\end{array}$ & $\begin{array}{l}998(203- \\
2276)\end{array}$ & 0.41 \\
\hline$<805$, No. $(\%)$ & & $23 / 49(46.9)$ & $18 / 31(58.1)$ & $5 / 18(27.8)$ & 0.07 \\
\hline CD3 + CD 4 + T cell (cells /ul) & $345-2350$ & $\begin{array}{l}515(65- \\
1661)\end{array}$ & $\begin{array}{l}\text { 484(65- } \\
1661)\end{array}$ & $\begin{array}{l}570(103- \\
1396)\end{array}$ & 0.43 \\
\hline$<345$, No. $(\%)$ & & 18/49(36.7) & $13 / 31(41.9)$ & $5 / 18(27.8)$ & 0.37 \\
\hline CD3 + CD8 + T cell(cells/ul) & $345-2350$ & $\begin{array}{l}366(81- \\
1029)\end{array}$ & $\begin{array}{l}341(81- \\
901)\end{array}$ & $\begin{array}{l}410(113- \\
1029)\end{array}$ & 0.28 \\
\hline$<345$, No. $(\%)$ & & $30 / 49(61.2)$ & 19/31(61.3) & $11 / 18(61.1)$ & 0.99 \\
\hline B cell count(cells /ul) & $240-1317$ & $\begin{array}{l}\text { 174(26- } \\
700)\end{array}$ & $\begin{array}{l}160(26- \\
700)\end{array}$ & $\begin{array}{l}198(44- \\
688)\end{array}$ & 0.37 \\
\hline$<240$, No. $(\%)$ & & $40 / 49(81.6)$ & 26/31(83.9) & $14 / 18(77.8)$ & 0.60 \\
\hline NK cell(cells/ul) & $210-1514$ & $\begin{array}{l}236(12- \\
866)\end{array}$ & $\begin{array}{l}221(12- \\
716)\end{array}$ & $\begin{array}{l}263(49- \\
866)\end{array}$ & 0.45 \\
\hline$<210$, No. $(\%)$ & & 28/49(57.1) & $20 / 31(64.5)$ & $8 / 18(44.4)$ & 0.17 \\
\hline \multicolumn{6}{|l|}{$\begin{array}{l}\text { Chest CT or X-ray findings } \\
\text { No. (\%) }\end{array}$} \\
\hline Normal & na. & $5(7.6)$ & $4(12.5)$ & $1(2.9)$ & 0.19 \\
\hline single & na. & $16(24.2)$ & $9(28.1)$ & $7(20.6)$ & 0.48 \\
\hline Bilateral distribution & na. & $45(68.2)$ & 19(59.4) & $26(76.5)$ & 0.14 \\
\hline \multicolumn{6}{|c|}{ IQR, interquartile range; erythrocyte sedimentation rate, ESR; na., not available; No., number. } \\
\hline
\end{tabular}


Table 3

Treatment and outcome of patients with COVID-19

\begin{tabular}{|c|c|c|c|c|}
\hline & \multicolumn{3}{|c|}{ No. (\%) } & \multirow{2}{*}{$\begin{array}{l}P \\
\text { value }\end{array}$} \\
\hline & Total $(n=66)$ & $D R V / c(n=32)$ & Control $(n=34)$ & \\
\hline Oxygen inhalation & $30(46.2)$ & $15(48.4)$ & $15(44.1)$ & 0.73 \\
\hline Corticosteroid & $28(42.4)$ & $12(37.5)$ & $16(47.1)$ & 0.43 \\
\hline \multicolumn{5}{|l|}{ Antiviral treatment } \\
\hline Arbidol & 26(39.4) & 10(31.3) & $16(47.1)$ & 0.19 \\
\hline Interferon inhalation & $14(21.2)$ & $8(25.0)$ & $6(17.6)$ & 0.47 \\
\hline \multicolumn{5}{|l|}{ Immune enhancer } \\
\hline Thymalfasin & $22(33.3)$ & $12(37.5)$ & $10(29.4)$ & 0.49 \\
\hline Immunoglobulin & $7(10.6)$ & $3(9.4)$ & $4(11.8)$ & 1.0 \\
\hline Fever during hospitalization & $40(60.6)$ & $14(43.8)$ & $26(76.5)$ & 0.01 \\
\hline Average fever days & $3.5(1-11)$ & $2.9(1-9)$ & $3.5(1-11)$ & 0.44 \\
\hline \multicolumn{5}{|l|}{ CT findings during hospital $\mathbb{Z}$} \\
\hline Progress within 5 days & 21/61(34.4) & $8 / 28(28.6)$ & 13/33(39.4) & 0.38 \\
\hline Improvement within 10 days & 49/61(80.3) & 25/28(89.3) & 2)4/33(72.7 & 0.12 \\
\hline Disease progression & $9(13.6)$ & $3(9.4)$ & $6(17.6)$ & 0.48 \\
\hline ICU & $2(3.0)$ & $1(3.1)$ & $1(2.9)$ & 1.0 \\
\hline 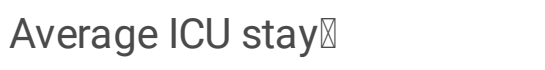 & 21 & 18 & 24 & / \\
\hline Mechanical ventilation & $2(3.0)$ & $1(3.1)$ & $1(2.9)$ & 1.0 \\
\hline 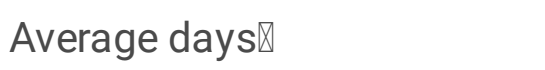 & 11 & 4 & 18 & / \\
\hline $\begin{array}{l}\text { Length of stay during } \\
\text { hospitalization }\end{array}$ & $13.1(3-39)$ & $12.9(3-34)$ & $13.4(4-39)$ & 0.78 \\
\hline \multicolumn{5}{|l|}{ Time to NAC(days) } \\
\hline TFTTNC & $9.1 \pm 7.8(1-36)$ & $7.8 \pm 6.0(1-25)$ & $\begin{array}{l}10.4 \pm 8.4(1- \\
36)\end{array}$ & 0.17 \\
\hline TFSTNC & $\begin{array}{l}15.4 \pm 8.1(2- \\
46)\end{array}$ & $\begin{array}{l}14.1 \pm 7.8(2- \\
36)\end{array}$ & $\begin{array}{l}16.7 \pm 8.4(3- \\
46)\end{array}$ & 0.21 \\
\hline
\end{tabular}


Table 4

CNACR after therapy

\begin{tabular}{|lcccccccccc|}
\hline & 3d & 6d & 9d & 12d & 15d & 18d & 21d & 24d & 27d & 30d \\
\hline DRV/C(n=31) & 11 & 17 & 22 & 24 & 28 & 28 & 29 & 30 & 31 & 31 \\
\hline CNACR (\%) & 35.5 & 54.8 & 71.0 & 77.4 & 90.3 & 90.3 & 93.5 & 96.8 & 100.0 & 100.0 \\
\hline Control & 7 & 13 & 19 & 21 & 25 & 30 & 31 & 31 & 31 & 31 \\
$(\mathrm{n}=33)$ & & & & & & & & & & \\
CNACR (\%) & 21.2 & 39.4 & 57.6 & 63.6 & 75.8 & 90.9 & 93.9 & 93.9 & 93.9 & 93.9 \\
P value & 0.20 & 0.21 & 0.26 & 0.23 & 0.12 & 1.0 & 1.0 & 1.0 & 0.5 & 0.5 \\
\hline CNACR: Cumulative nucleic acid conversion rate & & & & & \\
\hline
\end{tabular}

Table 5

Effect of symptom onset to admission time to NAC

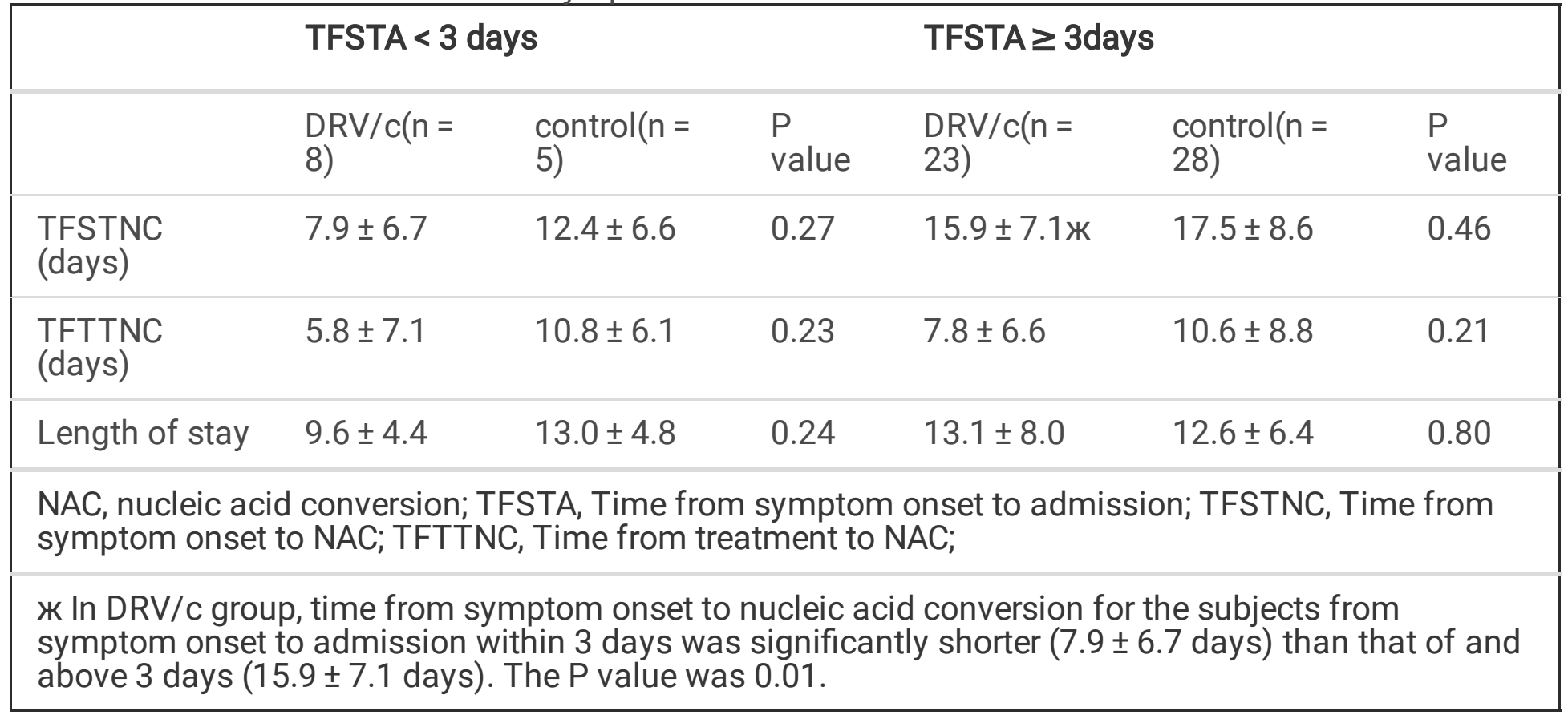

\section{Figures}



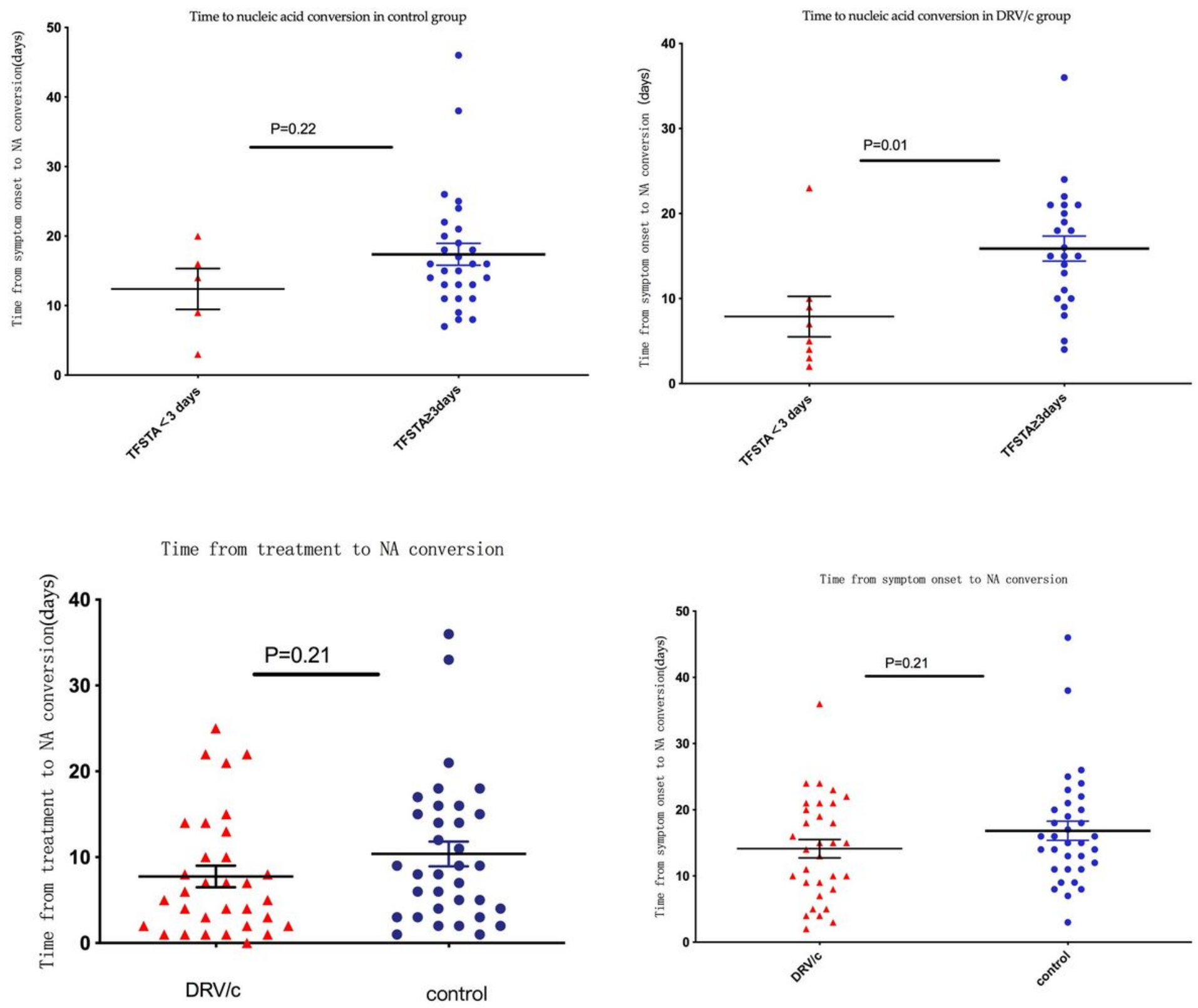

Figure 1

Time of nucleic acid conversion (day) 


\section{CNACR after therapy}

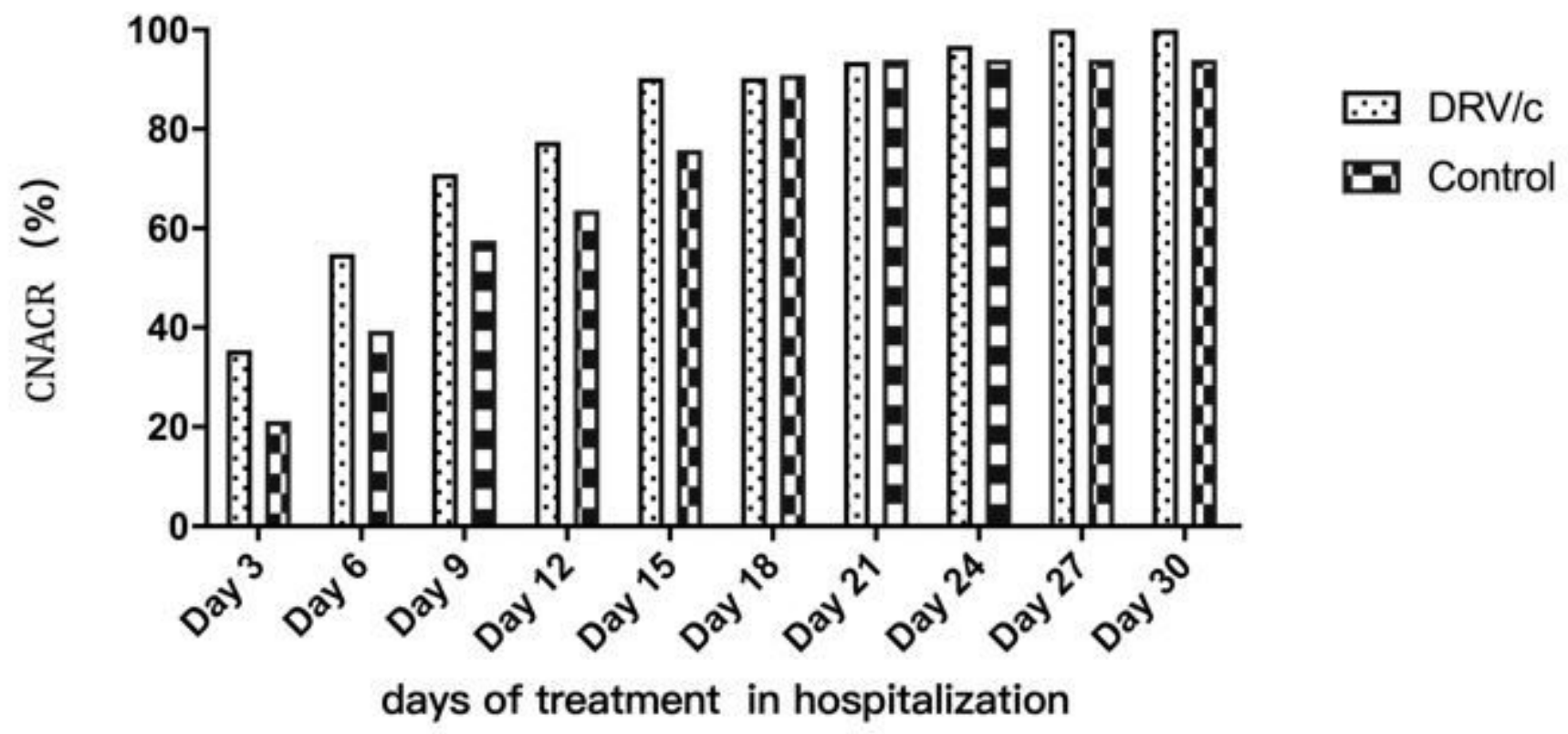

Figure 2

Cumulative nucleic acid conversion rate after therapy 

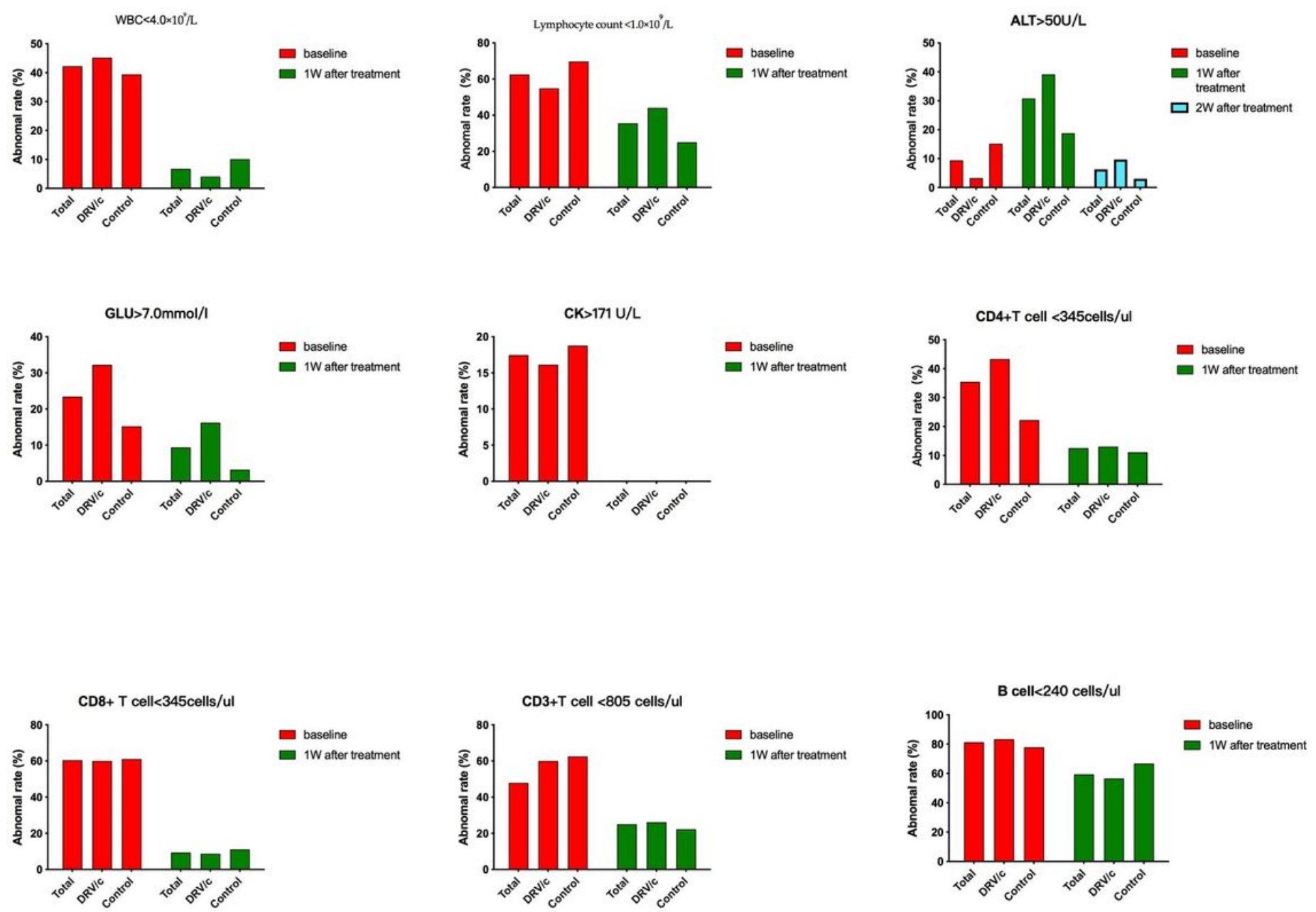

Figure 3

Abnormal rate of blood cells or biochemical indexes before and after treatment 